\title{
MODEL PEMBELAJARAN SOFT SKILLS TERINTEGRASI PADA SISWA SMK PROGRAM STUDI KEAHLIAN TATA BOGA
}

\author{
Siti Hamidah \\ Jurusan Pendidikan Tenik Boga dan Busana FT UNY \\ Hamidah siti66@yahoo.com
}

\begin{abstract}
Abstrak: Pembelajaran Soft Skills Terintegrasi pada Siswa SMK Program Studi Keahlian Tata Boga. Kajian model pembelajaran soft skills terintegrasi bertujuan untuk mengkaji model hipotetik dari pembelajaran soft skills siswa SMK Boga. Model dikembangkan berdasarkan kajian konsep-konsep soft skills dikaitkan dengan konteks pembelajarannya pada bidang tata boga. Soft-skills diidentifikasi dari kurikulum jasa boga kelompok produktif dan dieksplorasi dari dunia industri terkait. Kemudian soft skills dari hasil identifikasi ini diintegrasikan dengan pendekatan topik dan multi target. Implementasinya dalam pembelajaran menggunakan pendekatan psikologi pemebelajaran eklektik antara behaviourisme, kognitvisme, konstruktivisme, dan humanisme. Rancangan model ini menekankan peran aktif siswa mulai dari merancang perilaku soft skills, mengkonstruk soft skills terintegrasi melalui pengalaman belajar berbasis manajemen kinerja, dan melakukan refleksi untuk perbaikan berkelanjutan.
\end{abstract}

Kata kunci: pembelajaran, soft skils, terintegrasi, tata boga.

\section{SOFT-SKILLS INTEGRATED LEARNING MODEL FOR VOCATIONAL HIGH SCHOOL STUDENTS OF HOME ECONOMICS EDUCATION}

\begin{abstract}
Soft-skills Integrated Learning Model for Vocational High School Students of Home Economics Education. This study of soft-skills integrated learning model was aimed at investigating a hypothetic model of learning for Vocational High School students of home economics education. The model was developed from concepts of soft-skills as well as the learning within the context of home economics education. The soft-skills were identified through out of the curriculum of vocation for food service program as well as through out demanded soft skills by industries partners. The identied soft skills then, integrated into the curriculum by using topics and muli-target approaches. This model is implemented by eclecitally combining among these four psychological approaches. This model design indeed encouraging students actively ranging from pre-determined soft skills to be achieved, constructing integrated soft skills through learning experience based on performance management, and reflecting for a sustainable improvement of student soft skills
\end{abstract}

Keywords: learning, soft skills, integrated.

\section{PENDAHULUAN.}

Berbagai perubahan yang relatif cepat dalam bidang ekonomi, dunia kerja, masyarakat maupun budaya menuntut dimilikinya kompetensi esensial bagi tenaga kerja yang relevan diberbagai tingkat dan kondisi pekerjaan. Pada abad 21 ini muncul adanya perspektif bahwa tenaga kerja muda tidak cukup hanya memiliki pengetahuan dasar yang terkait dengan tiga "R's" (reading, writing, and arithmetic) sebagai modal kemampuan bekerja, namun juga perlu memiliki keterampilan aplikatif. Selanjutnya dinyatakan bahwa "soft skills adalah kompetensi yang sangat penting bagi tenaga kerja untuk siap bekerja dan membantu beradaptasi pada situasi kerja" (www.dol.gov/odep/2009/01/03). Karenanya untuk menghadapi era kompetitif, soft skills adalah kompetensi esensial dan merupakan kunci keberhasilan bagi tenaga kerja 
di tempat kerja dan untuk pengembangan diri (Kaipa \& Milus. 2005:1; Mitchell. 2008:1).

SMK sebagai salah pendidikan berorientasi dunia kerja merupakan salah satu pendidikan vokasi untuk menghasilkan sumberdaya manusia berkelas dunia. Lulusannya diarahkan sebagai tamatan siap kerja, cerdas, memiliki keunggulan kompetitif dan komparatif serta berkarakter kuat sebagai pekerja profesional. Dengan sendirinya soft skill harus terkuasai manakala ingin menjadikan lulusan yang unggul dalam menghadapai persaingan kerja. Ajir Chaturdevi, et al. (2011) mengemukakan bahwa penguasaan skills lulusan yang berhubungan dengan pekerjaan tidaklah cukup, karena penguasaan soft skills adalah penting terutama untuk bisnis. Demikian halnya Helmlinger menjelaskan bahwa tenaga kerja di bidang hospitality yang hanya menguasai hard skills saja menjadikan gagal dan sering mengulangi kesalahan yang sama (http://hiring.inc.com/columns.html/2007/04/26).

Didik Purwanto (Kedaulatan Rakyat, September 2008:13) mengemukakan bahwa kemampuan soft skills sangat dibutuhkan di dunia Industri dan sangat menentukan untuk bisa diterima dalam dunia kerja. Kemampuan itu antara lain, kepemimpinan, kreativitas, manajerial. Dengan demikian lulusan SMK harus menguasai soft skills karena, tuntutan kerja dan tantangan kerja.

Sudah saatnya pembelajaran soft skills integrasi menjadi kebutuhan, hal ini didasari keadaan bahwa proses pembelajaran selama ini lebih menekankan aspek hard skills. Penekanan penguasaan hard skills semata-mata dengan alasan bahwa penguasaan hard skills lebih mudah diamati dan lebih cepat terlihat hasilnya, sementara soft skills tidak mudah dalam mengajarkannya, sulit diamati dan diukur
(Coates. 2006:1). Disisi lain dinyatakan bahwa pelatihan soft skills mampu meningkatkan penguasaan skill teknik (Ajir Chaturdevi, et.al 2011:5). Pelatihan soft skills memperbaiki potensi seseorang, membuat tenaga kerja lebih fleksible, memiliki sikap positip untuk mudah berubah, mampu menangani berbagai perubahan tuntutan kerja dan lebih kompetitif (Rani, 2010:4).

Melalui diskusi dengan beberapa guru di berbagai SMK di DIY ditemukan bahwa guru belum memiliki kemampuan yang memadai dalam mengelola pembelajaran soft skills di tingkat kelas, mereka juga masih mengalami kesulitan saat melakukan evaluasi soft skills. Kinerja siswa di kelas terutama saat praktek menunjukkan bahwa sebagian besar belum mampu bekerja efisien, berorientasi pada mutu, dan komitmen pada hasil yang terbaik. Karenanya diperlukan suatu model pembelajaran yang dapat mengintegrasikan antara hard skills sebagai kemampuan teknik dan soft skills sebagai pendukung kinerja siswa saat praktek. Hal ini didasari oleh keyakinan bahwa penguasaan soft skills yang baik mampu mendorong penguasaan hard skills secara lebih baik pula.

Model yang dirancang ini memungkinkan siswa memperoleh pengalaman dalam prespektif yang lebih luas baik menyangkut permasalahan - permasalahan yang dikembangkan dalam pembelajaran maupun kemampuan - kemampuan lain seperti berfikir kritis, kreatif, memecahkan masalah, pengembangan personal, komunikasi. mengembangkan rasa ingin tahu. Melalui model ini pula memungkinkan siswa lebih terlibat secara langsung dalam setiap pengalaman belajar, memotivasi siswa untuk bertanya, dan 
mengetahui secara lebih lanjut materi yang dipelajari. Pada akhirnya memfasilitasi peningkatan perfoma kerja ataupun pembelajaran diri, peningkatan kualitas kerja yang sesuai dengan standar kerja ataupun mengatasi persoalan kerja yang bisa datang secara tiba-tiba.

\section{DASAR PENGEMBANGAN MODEL}

\section{Konsep soft skills}

Secara umum soft skills adalah sekelompok sifat kepribadian, ataupun kemampuan yang diperlukan seseorang agar secara efektif dapat bekerja ditempat kerja, dan meningkatkan diri (wikipedia, com. 2008: 1; Kelly, tth: 5; Leung, 2008: 1; Lynch, tth: 419). Soft skills adalah kunci untuk meraih kesuksesan, termasuk didalamnya kepemimpinan, pengambilan keputusan, penyelesaian konflik, komunikasi, kreatifitas, dan kemampuan presentasi (Kaipa, tth: 5-6). Soft skills adalah skills yang memungkinkan seseorang meraih potensi dirinya dan menggunakan pengetahuannya secara bermanfaat dan terintegrasi dalam kehidupannya. (Yate, 2005: 1). Soft skills adalah kombinasi perilaku, yang meliputi sikap dan motivasi yang menggerakan perilaku. (Helmlinger, th: 2). Dengan demikian dapat dinyatakan bahwa soft skills merupakan sifat kepribadian yang menjadi kunci meraih kesuksesan dan berfungsi untuk meningkatkan efektifitas dalam bekerja.

Bila soft skills ditinjau dari komponen soft skills, terbagi menjadi skills interpersonal dan interpersonal. Kecakapan intrapersonal merupakan aspek-aspek skills yang menjelaskan tentang kemampuan untuk mengelola diri sendiri manakala yang bersangkutan berada pada situasi kerja. Kecakapan interpersonal merupakan aspek skills yang menjelaskan kemampuan untuk mengelola lingkungan kerja sehingga dirinya mampu beradaptasi dengan situasi kerja.

Model pembelajaran soft skills terkait dengan kompetensi yang dibutuhkan oleh industri yang bergerak dalam bidang keramahtamahan/Hotel, tercermin pada kompetensi personal yang efektif yang meliputi : personal effectiveness competency yang meliputi interpersonal skills, integrity, professionalism, initiative, willingness to learn, dan dependability dan reliability. (http://www.careeronestop.com/competency/Mod el/pyramidaspx $?=y \underline{18 / 01 / 2009}$ ).

\section{Pendekatan Pembelajaran Soft Skills.}

Pembelajaran soft skills yang akan dikembangkan ini menggunakan beberapa pendekatan pembelajaran behavioural, construktivistik, cognitive dan humanism yang digunakan secara bertautan atau eklektik.

Dengan pendekatan pembelajaran behaviorism maka pembelajaran soft skills dapat lebih efektif manakala diikuti dengan konsekuensi perilaku apakah berupa efek yang menguntungkan dan tidak menguntungkan. Dengan pendekatan konstruktivistik maka proses belajar menekankan upaya siswa membentuk pemahaman, kemampuan mengkonstruk apa yang dipelajari. Pengetahuan berproses untuk menjadi, melalui tahap interpretasi, transformasi, konstruksi yang dilakukan oleh siswa sendiri. Siswa akan memperoleh makna yang dalam tentang apa yang diketahui dan sekaligus menguatkan tentang konsep diri. Kekuatan belajar berasal dari diri sendiri di kontrol oleh guru, materi dan standar pencapaian Dengan pendekatan cognitive belajar menekankan pentingnya subyek belajar dalam memperoleh dan mengorganisasikan pengetahuannya. Belajar terjadi dalam diri siswa proses mental dari 
persepsi, mengingat, berfikir, mengambil keputusan. Proses mental sifatnya individual, tidak tergantung pada ada tidaknya penguatan. Dengan pendekatan humanisme memandang bahwa setiap siswa memiliki potensi yang harus dikembangkan melalui pendidikan. Setiap siswa adalah pribadi yang memiliki potensi diri, ada kesadaran tentang siapa dirinya. Pembelajaran meletakkan siswa sebagai pusat pembelajaran, pembelajaran melalui proses active selfdiscovery, sehingga siswa memiliki kewenangan untuk tumbuh dan berkembang. Kunci sukses pembelajaran ini bahwa pembelajaran berdasarkan pengalaman dengan melibatkan personal, merangsang perasaan dan fikiran, self initiation, juga evaluasi diri atau dengan pembelajaran aktif. Pembelajaran aktif adalah kuncinya dan direfleksikan melalui evaluasi" (Walker,1997:109).

\section{Pembelajaran Terintegrasi}

Pembelajaran soft skills terintegrasi menekankan pada penguasaan soft skills terpadu dengan penguasaan hard skills. Fogarty, (1991:xiv) menjelaskan pendekatan integrasi kurikulum diantaranya adalah: pengintegrasian dalam satu disiplin dengan dua model yaitu connected, dan nested. Connected model, merupakan model kurikulum yang menggunakan keterkaitan setiap subyek, materi ajar, dengan connected model pembelajaran soft skills akan lebih bermakna bagi penguatan hard skills. Nested model berorientasi pada pencapaian multiple skills dan multiple target. Dengan model ini pembelajaran soft skills akan mudah tercapai, karena soft skills terintegrasi secara tidak dipaksakan. Setiap kegiatan pembelajaran termuati soft skills dan terukur melalui target pembelajaran. Siswa akan menikmati pembelajaran soft skills melalui tugas yang dirancang dan difasilitasi guru, secara individual siswa dapat mengembangkan diri melalui tugas dan penguasaan hasil belajar lebih kaya.

Integrasi soft skills kedalam hard skills melalui topik-topik atau unit materi, dikembangkan dari inti mata diklat produktif kompetensi keahlian jasa boga serta kebutuhan soft skills industri. Selain itu integarsi soft skills pada mata pelajaran produktif disesuaikan dengan kebutuhan standar kompetensi dan kompetensi dasar yang akan dikembangkan guru.

\section{Pembelajaran Soft Skills Sebagai Proses Pembudayaan.}

Pembelajaran soft skills merupakan bagian dari upaya membentuk kepribadian dengan sendirinya memerlukan proses berkelanjutan sebagai proses pembudayaan. Proses pembudayaan ini dibangun melalui beberapa tahap mulai dari membangun konsep sampai adanya pemaknaan tentang apa yang dipelajari, termasuk didalamnya membangun self-concept. Kapp dan Hamilton (2006) menekankan bahwa pembelajaran soft skills memerlukan pengorganisasian belajar jangka panjang agar mencapai tahap sukses. Pembelajaran terfokus dari learning as acquisition ke learning by interaction. Belajar menjadi pemimpin harus disemai dengan memimpin, bukan hanya diperoleh melalui membaca.Demikian halnya Kreitner dan Kinicki (2008: 234) menyatakan bahwa upaya meningkatkan unjuk kerja secara individual tertata dalam format manajemen performen dalam siklus perbaikan yang berkelanjutan yang berfungsi untuk memperbaiki performen kerja sebagai perwujudan dari hasil akhir target pelatihan. 


\section{Strategi pembelajaran soft skills terintegrasi.}

Joyce dan Weil (2009:7) menggunakan istilah strategi instruksional sama dengan model pembelajaran. Pembelajaran merupakan bentuk membelajarkan siswa, membantu siswa memperoleh informasi, skills, nilai, cara berfikir sehingga siswa mampu mengekspresikan diri, kapabilitas untuk belajar semakin baik. Dengan demikian strategi pembelajaran terintegrasi tidak hanya sekedar menterjemahkan kurikulum kedalam rencana kegiatan pembelajaran, mengorganisasikan materi, ataupun menfasilitasi pembelajaran dengan beragam metode pembelajaran namun menunjuk pada pola pembelajaran terintegrasi untuk mengembangkan kemampuan siswa untuk belajar atau mengembangkan kapabilitas siswa untuk terus belajar. Keadaan ini akan memunculkan tata nilai pada diri siswa yang mendorong perilaku kerja terstandar.

Sejalan dengan pola integrasi connected dan nested maka ada tiga hal penting terkait dengan penetapan strategi pembelajaran. Pertama, analisis kompetensi dasar menjadi dasar penetapan tujuan pembelajaran. Tujuan yang dirumuskan harus dapat menggambarkan integrasi hard skills dan soft skills, serta penetapan standar pencapaian terutama untuk soft skills. Tujuan adalah menjelaskan content yang mendiskripsikan keluasan unit, materi ajar terintegrasi yang akan dipelajari siswa. Content dapat berupa standar hasil belajar, taksonomi belajar, dimensi belajar, analisis tugas serta teknologi dan media pembelajaran yang digunakan (Shambaugh \& Magliaro. 2006: 54).

Kedua, pemahaman yang benar profil soft skills siswa sebagai dasar penentuan kegiatan pembelajaran terutama untuk mengaktifkan siswa sejak awal sebagai bagian dari proses pembudayaan. Siswa dipersiapkan mental dan fisiknya melalui pemahaman setiap soft skills yang akan dilatihkan, serta rancangan aktivitas belajar.

Ketiga adalah pengalaman belajar yang berfungsi untuk meningkatkan penguasaan soft skills dan hard skills secara terintegrasi. Pada dasarnya membentuk perilaku soft skills terintegrasi didasari oleh konsekuensi yang disemai dalam lingkungan pembelajaran yang sengaja diciptakan guru. Sejumlah penelitian menyebutkan pentingnya pembelajaran soft skills bagi tenaga kerja di dalam situasi nyata. Cooton, (2001) menekankan pentingnya dukungan replika situasi kerja dan tugas yang diberikan mendekati unjuk kerja di dunia kerja. Pembelajaran diselenggarakan dengan waktu yang relatif lama dengan perbaikan berkelanjutan.

Secara jelas tersaji dalam sintak berikut: 
Tabel 1. sintak pembelajaran soft skills terintegrasi.

\begin{tabular}{|c|c|c|c|c|}
\hline \multirow[t]{2}{*}{ No } & \multirow[t]{2}{*}{ Tahapan } & \multirow{2}{*}{ Prosedur } & \multicolumn{2}{|c|}{ Peran } \\
\hline & & & Guru & Siswa \\
\hline 1 & $\begin{array}{l}\text { Perencanaan } \\
\text { pembelajaran } \\
\text { terintegrasi }\end{array}$ & $\begin{array}{l}\text { - Menentukan topik dan sub topik, } \\
\text { selanjutnya di susun dalam peta } \\
\text { topik. } \\
\text { - Menentukan soft skills yang akan } \\
\text { dilatihkan dan memahami konsep } \\
\text { setiap soft skills. } \\
\text { - Merancang aktivitas } \\
\text { pembelajaran setiap soft skills } \\
\text { yang akan dilatihkan } \\
\text { - Menentukan target pembelajaran } \\
\text { - Membuat RPP terintegrasi. }\end{array}$ & $\begin{array}{l}\text { - Penentu soft skills yang } \\
\text { dilatihkan berdasarkan } \\
\text { kajian kurikulum dan } \\
\text { situasi kelas. } \\
\text { - Menetapkan target belajar } \\
\text { sebagai standar } \\
\text { - Membuat skenario } \\
\text { pembelajaran } \\
\text { - Mengontrol sumber } \\
\text { belajar. }\end{array}$ & $\begin{array}{l}\text { - Memahami konsep } \\
\text { soft skills dan } \\
\text { perilakunya. } \\
\text { - Membuat kontrak } \\
\text { belajar } \\
\text { - Bila perlu } \\
\text { membentuk } \\
\text { kelompok kerja }\end{array}$ \\
\hline 2 & Implementasi & $\begin{array}{l}\text { - Menumbuhkan konsep soft skills } \\
\text { sebagai bentuk awareness. Ada } \\
\text { kesadaran akan target } \\
\text { pembelajaran. } \\
\text { - Menekanakan pada situasi } \\
\text { praktek } \\
\text { - Manajemen penguatan } \\
\text { - Pembelajaran berbasis } \\
\text { kemandirian }\end{array}$ & $\begin{array}{l}\text { - Memfasilitasi } \\
\text { pembelajaran yang kaya } \\
\text { pengalaman dan dalam } \\
\text { situasi kerja } \\
\text { - Membimbing dan } \\
\text { memonitor pembelajaran } \\
\text { - Menjelaskan kesalahan } \\
\text { perilaku soft skills dan } \\
\text { mendorong untuk } \\
\text { memperbaiki diri. } \\
\text { - Menerapkan manajemen } \\
\text { penguatan } \\
\text { - Memotivasi }\end{array}$ & $\begin{array}{l}\text { - Berinteraksi dengan } \\
\text { situasi } \\
\text { pembelajaran } \\
\text { - Membangun } \\
\text { struktur kognitifnya } \\
\text { dengan } \\
\text { mengkonstruk } \\
\text { konsep soft skills } \\
\text { - Mengontrol } \\
\text { perilaku menuju } \\
\text { pada penguasaan } \\
\text { yang sempurna. } \\
\text { - Taat pada kontrak } \\
\text { belajar }\end{array}$ \\
\hline 3 & $\begin{array}{l}\text { Refleksi, } \\
\text { observasi } \\
\text { dan evaluasi } \\
\text { antar teman }\end{array}$ & $\begin{array}{l}\text { - Memonitor perkembangan } \\
\text { ketercapaian soft skills } \\
\text { - Dilakukan secara berkelanjutan } \\
\text { - Dievaluasi secara bertahap awal, } \\
\text { tengah dan akhir }\end{array}$ & $\begin{array}{l}\text { - Mempelajari perangkat } \\
\text { evaluasi. } \\
\text { - Melakukan refleksi dan } \\
\text { evaluasi secara } \\
\text { berkelanjutan } \\
\text { - Menggunakan hasil } \\
\text { observasi, refleksi dan } \\
\text { evaluasi antar teman } \\
\text { untuk perbaikan } \\
\text { berkelanjutan. }\end{array}$ & $\begin{array}{l}\text { - Menunjukkan } \\
\text { penguasaan soft } \\
\text { skils } \\
\text { - Merefleksi } \\
\text { performence soft } \\
\text { skills secara } \\
\text { mandiri. } \\
\text { - Meningkatkan } \\
\text { performen kerja }\end{array}$ \\
\hline
\end{tabular}

\section{Sistem evaluasi pembelajaran soft skills}

Pembelajaran soft skills ditekankan pada penguasaan aspek afektif, aspek pribadi meliputi komponen personal dan interpersonal. Dikarenakan pembelajaran soft skills diselenggarakan dalam situasi yang berkelanjutan, continues process, maka evaluasi dilakukan dalam tiga tahap sebelum, selama dan sesudah pembelajaran atau measure ongoing performance. Hal ini dimaksudkan untuk memperoleh berbagai informasi secara berkelanjutan perkembangan siswa dari sisi kognitif dan skill. Selain itu untuk meyakinkan bahwa penguasaan kompetensi soft skills telah mencapai tingkat mastery, menunjukkan performa kerja yang terstandar.. Melalui mekanisme evaluasi dengan pendekatan perbaikan berkelanjutan ini, performa kerja soft skills siswa akan tercapai secara maksimal dan selaras dengan kebutuhan stakeholder.

Pengukuran soft skills menggunakan alat ukur non tes, berupa studi persepsi, pendapat dan kategori. Instrumen yang digunakan dipilih dengan pertimbangan saling melengkapi seperti observasi, angket, portofolio, ekspresi diri, self evaluation. Format evaluasi dibuat agar dapat dipergunakan oleh guru, teman, dan diri sendiri. 
Pengembangan instrumen ditentukan oleh dimensi masing-masing berdasarkan kedalaman dan keluasan. Kajian tentang masing-masing dimensi ditentukan oleh materi ajar yang menggambarkan soft skills terintegrasi. Hasil evaluasi akan memberi gambaran perkembangan perubahan penguasaan soft skills dibandingkan dengan standar.

\section{KAJIAN MODEL}

Model pembelajaran soft skills terintegrasi merupakan model yang mampu menyatukan hard skills dan soft skills secara seimbang baik pada saat guru merancang pembelajaran, mengimplementasikan dan mengevaluasi. Model pembelajaran dapat dilakukan guru dengan mudah karena soft skills terintegrasi pada topiktopik hard skils yang menjadi inti kompetensi jasa boga.

Model integrasi diawali dengan kajian soft skills hasil analsis kebutuhan soft skills dari industri dan kebutuhan kurikulum. Selanjutnya temuan soft skills tersebut diintegrasikan kedalam topik-topik hard skills yang menjadi content. Integrasi soft skills ini juga terdiskripsikan kedalam tujuan pembelajaran dan pada diri siswa serta pengalaman pembelajaran. Tujuan pembelajaran menjadi dasar bagi siswa dan guru dalam memahami target belajar sekaligus sebagai penuntut siswa akan standar kerja soft skills dan hard skills atau multi target (nested). Integrasi pada diri siswa menjelaskan proses internalisasi yang terjadi sejalan dengan waktu dan mekanisme pembelajaran yang dikreasikan guru. Pengalaman belajar merupakan implementasi dari proses pembudayaan yang menekankan pada manajemen performen.

Model pembelajaran soft skills yang akan dikembangkan bertumpu pada pembelajaran kognitivism, construktivism, behaviourism, dan humanism yang digunakan secara eklektik. Karena itu selama pembelajaran siswa dikembangkan konsep soft skills, kemampuan berfikir kritis, belajar melalui fakta-fakta yang ditemui pada saat praktek, mencoba menganalisis dan membuat pernyataan-pertanyaan untuk meneguhkan perilaku soft skills. Hal ini dilakukan melalui diskusi, refleksi diri ataupun menganalisis balikan, harapannya penguasaan konsep soft skills siswa semakin kokoh. Situasi pembelajaran yang diciptakan guru harus mampu menumbuhkan, menjaga maupun menguatkan soft skills. Pola penguatan dapat dikembangkan guru sebagai bentuk dari konsekuensi perilaku yang ditampilkan selama pembelajaran.

Implementasi pembelajaran dalam format belajar aktif baik saat tatap muka teori ataupun praktek. Strategi pembelajaran yang dikembangkan berbasis pemecahan masalah, artinya soft skills terintegrasi ditumbuhkembangkan melalui tugas yang dikerjakan secara kelompok ataupun madiri. Proses pembelajaran menunjuk pada aktivitas pembelajaran yang mendiskripsikan baik peran guru, siswa dan lingkungan belajar yang diciptakan guru. Peran guru sebagai pengelola pembelajaran menolong siswa dalam merancang perilaku soft skills sebagai target belajar, menumbuhkan keinginan dan semangat untuk mewujudkan soft skills selama proses pembelajaran. Guru harus mampu menumbuhkan motivasi siswa akan nilai pentingnya penguasaan soft skills dihubungkan kepentingan kerja, ataupun dengan kesuksesan kerja. Guru harus mampu memfasilitasi kepentingan belajar siswa dan menjadikan dirinya coaching yang baik yang mampu 
menumbuhkan potensi soft skills siswa dan kebermaknaannya untuk bekerja. perencanaan, implementasi dan evaluasi seperti tersaji sebagai berikut:

Desain model hipotetik yang menggambarkan keterkaitan komponen pembelajaran soft skills terintegrasi yang meliputi

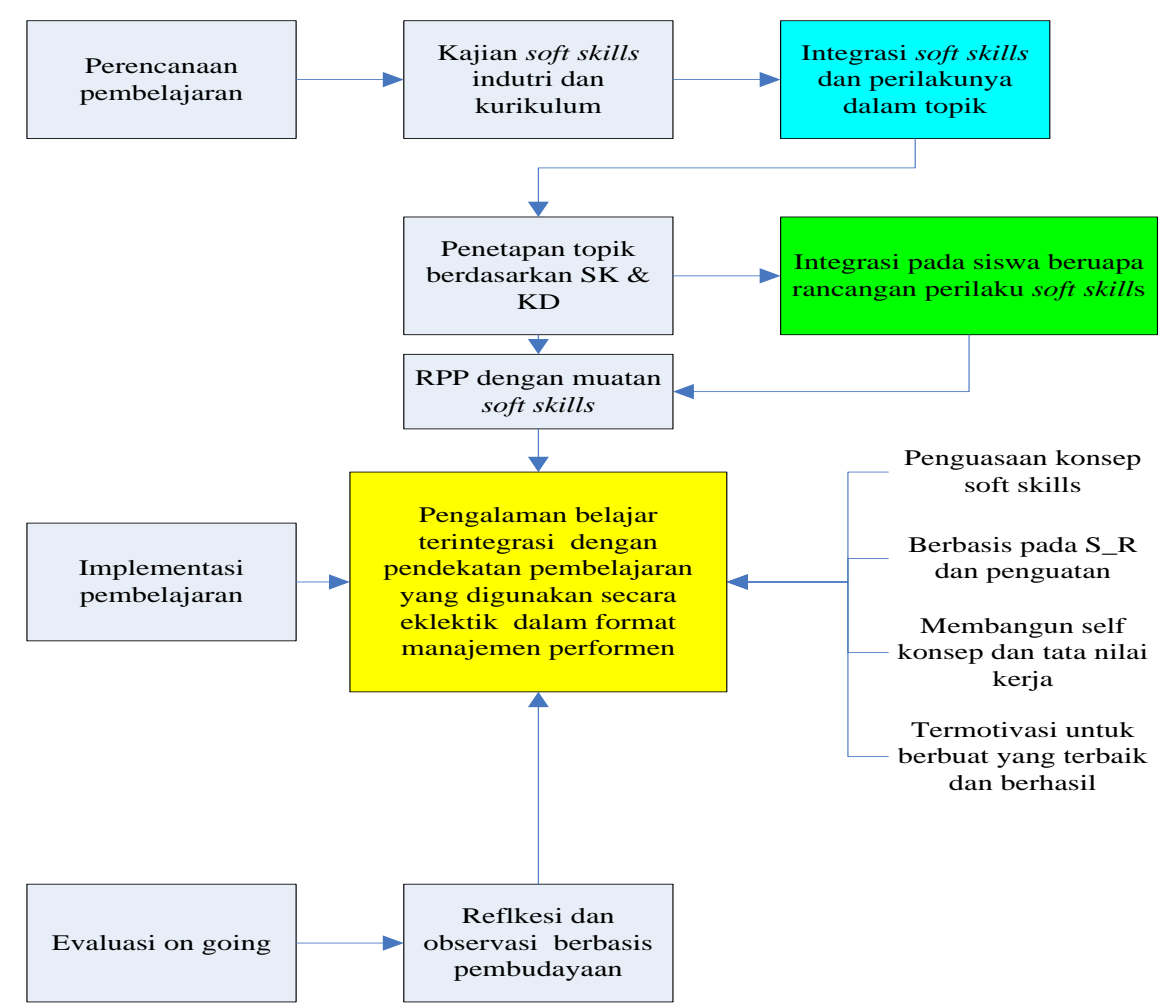

Gambar 1. model hipotetik pembelajaran soft skills terintegrasi

Dalam gambar di atas terlihat: ada tiga bagian model: komponen perencanaan pembelajaran, pengalaman serta komponen evaluasi. Komponen perencanaan mulai dari kajian soft skills, penetapan topik dan rancangan RPP. Termasuk didalamnya rancangan aktivitas siswa untuk membuat perilaku soft skills yang akan diimplementasikan dalam pembelajaran. Rancangan model juga memperlihatkan komponen integrasi meliputi: integrasi pada siswa sebagai wujud mempersiapkan siswa mengikuti pembelajaran berbasis soft skills. komponen implementasi menjelaskan pengalaman belajar dengan pendekatan pembelajaran yang digunaan secara eklektik, berbasis pengalaman, berbasis pembudayaan yang terwujud dalam manajemen performen. Manajemen performen merupakan wujud dari peran guru sebagai fasilitator dan coach yang membantu siswa mencapai derajad penguasaan soft skills yang mastery dan konsisten. Dengan kata lain rancangan kegiatan mengajar soft skills yang dilatihkan diimplementasikan selama pembelajaran, sebagai wujud dari perbaikan berkelanjutan.

Demikian halnya evaluasi ongoing menjadikan siswa mampu merefleksi pencapaian setiap soft skills yang berfungsi sebagai bagian 
dari internalisasi diri dan sekaligus memotovasi diri untuk berbuat yang lebih baik. Bagi guru evaluasi ini sebagai upaya mengarahkan siswa mencapai target pembelajaran, sekaligus untuk menginformasikan pencapaian performen siswa sebagai wujud dari mekanisme coaching. Alat evaluasi yang digunakan lembar observasi, rubrik dan penilaian antar teman.

\section{KESIMPULAN}

Model pembelajaran hipotetik yang telah dikembangkan memungkinkan penguasaan soft skills kearah konsisten. Hal ini dimungkinkan adanya proses integrasi mulai dari rancangan belajar siswa, implementasi dan evaluasi on going yang didasari semata-mata oleh perbaikan berkelanjutan atau manajemen performen.

\section{UCAPAN TERIMA KASIH}

Dengan ini saya mengucapkan terima kasih kepada redaktur Jurnal Pendidikan Vokasi yang bersedia menerbitkan artikel ini.

\section{DAFTAR PUSTAKA}

Ajir Chatuvedi, et al. (2011). Communicative approach to soft \& hard skills. Journal VSRD-International of bussiness \& management research Vol 1 (1), 2011. Diambil pada tanggal 11 Mei 2011, dari www.visualsoftindia.com/journal. Html

Coates, E.D. (2006). People skills tarining. Diambil pada tanggal 15 Agustus 2010, dari www.initforlife.com

Consortium for entrepreneurship education. (2009). Competency model clearinghouse hospitality/hotel and lodging competency model. Diambil pada tanggal 4 Maret 2009, dari

http://www.careeronestop.org/competenc yModel/ pyramid.aspx?HSP=y

Cooton, K. (2001). Developing employability Skills. Diambil pada tanggal 1 April 2008, dari Http://www/nwer/org/scpd/sirs/8/c015ht $\underline{\mathrm{ml}}$
Dibanding IPK soft skills lebih dibutuhkan industri. (12 September 2008) Kedaulatan rakyat $\mathrm{P} 4$

Forgarty, R. (1991). How to integrate the curricula. Illinois : IRI/Skylight Publishing, Inc.

Helmlinger, W. (tth). Do you employee possess the right competencies? Diambil pada tanggal 26 April 2007 dari http://hiring.inc.com/columns.html

Joyce, B., \& Weil.M. (1996). Models teaching. Boston: Allyn \& Bacon A. Simon \& Schuster Company.

Kaipa.P., \& Milus.T.(2005). Soft skills are smart skills. Diambil pada tanggal 16 Oktober 2010 dari http://kaipagroup.com/article/soft skills .pdf

Kapp M. K.,\& Hamilton, B. (2006). White paper : Designing Instruction to Teach Principles (soft skill). Institut for Interactive Technologies . Diambil pada 2 September 2010, dari http//wwwKarkapp.com/materials/teachi ng\%20Principles Pdf.

Kelly, A. (tth ). Soft skills development in the Irish economy. FAS. The National Training and Employment Authority. Irish. Diambil pada tanggal 20 Februari 2009, dari http://www.fas.ie/en/pubdocs/SoftSkillsD evelopment.pdf

Kreitner, R., dan Kinicki, A.(2008). Organizational behaviour edisi 8. New York: McGraw-Hill International Edition.

Leung, L. (2008). How teached can broaden their soft skills. New York: IT Career and Training Alert newsletter.

Lynch, K. (tth). Collaborative work skillls for begining IS professional.

Australia:Monash University, Caulfield, Australia. Diambil tanggal 29 Juni 2008, dari http://proceding.informingscince.org/insit e/066lynch.pdf.

Mitchell, W.G. (2008). Essential soft skills for success in the twenty-first century workforceas perceived by business educators. Diambil 8 Mei 2011, dari etd.auburn.edu/etd/bitstream/handle/1041 5/1441/mitchell_Geana_57.pdf?sequenc. 
Office of Disability Employement Policy

(ODEP). (tth). Essential skills to getting a job, what young people with disability need to know. Diambil pada tanggal 1 Maret 2009, dari www.dol.gov/odep.

Rani, E.M.S. (2010). Need and importance of soft skills in student. Vol,-II 3 Januari-Juni (Summer) 2010. Associate Professor in English, Sri Sarada College for Women, Salem- 636016

Shambaugh, N., \& Magliaro, G.S. (2006). Instructional design a systematic approach for reflective practice. Boston: Pearson Education Inc
Wikipedia. (2008) Soft skills the free encyclopedia. Diambil 29 Juni 2009, dari en.Wikipedia.org/wiki/soft_skills

Walker, S.I. (1997). Teaching training and learning practical guide. Great Britain: Publisher Business Education

Yates, L. (2005). Fact sheet generic skills.

AMEP Research centre. Diambil 29 juni 2009, dari

http://www.ameprc.mq.edu.au/docs/fact sheets/0

4TeachingIssuesforWebpdf. 